\title{
The nature of collaboration and perceived learning in wiki-based collaborative writing
}

Chun Lai

The University of Hong Kong, Hong Kong

Chunlin Lei

Shanghai University of International Business and Economics, P. R. China

Yang Liu

Tianjin University, P. R. China

\begin{abstract}
Wiki-based collaborative writing has been widely adopted in education to facilitate collaborative learning. However, research shows that students adopt different collaboration patterns during wiki-based collaborative writing, and that collaboration patterns may vary in how they enhance learning. It is thus critical to understand the relationship between the nature of collaboration and learning. This study examined 95 university English as foreign language (EFL) learners' performances in wiki-based collaborative writing projects. Analyses of the student survey and interview responses and students' archived performances on the wiki platform showed that they adopted three collaboration approaches, and that the approach featuring high equality and mutuality was associated with the greatest enjoyment of, perceived learning from, and positive attitudes towards collaborative writing. The study further found that equality and mutuality exert different impacts on different learning outcomes, and that labour division and peer contribution during collaboration determine the learning potential of collaborative writing for EFL students.
\end{abstract}

\section{Introduction}

Collaborative writing has been embraced in education as a means to generate and support knowledge coconstruction; a pedagogy that facilitates deep learning and a communication channel that stimulates learner autonomy, creativity and critical thinking (Hodges, 2002; Lowry, Curtis, \& Lowry, 2004; Nevid, Pastva, \& McClelland, 2012). In language education, collaborative writing is advocated as an important mechanism for individual writing development (Hodges, 2002), as joint construction enables collaborative dialogues about language and collective scaffolding that help learners to develop better understanding of language and writing conventions than they could obtain on their own (Storch, 2011; Swain, 2010). Collaborative writing has been found not only to generate higher-quality writing products than individual writing (Dobao, 2012; Oh, 2014; Shehadeh, 2011), but also to benefit individuals' development of writing skills (Chao \& Lo, 2011; Shehadeh, 2011). The positive impact might be attributed to a dialectic process that engages students in collective scaffolding and assists writing development through enhanced content generation and organisation, enriched language and structure use, and the development of second-language (L2) proficiency in general (Kost, 2011; Storch, 2013; Wigglesworth \& Storch, 2012; Woo, Chu, Ho, \& Li, 2011).

Wikis, with functionalities that facilitate peer interaction and collaborative content construction (Roussinos \& Jimoyiannis, 2013), have been used to support collaborative writing. Wiki-based collaborative writing has been perceived positively as a motivating approach to learning and an effective way to enhance L2 writing development (Chao \& Lo, 2011; Kost, 2011; Li \& Zhu, 2013). Research has examined L2 learner perceptions of the writing experience, their revision behaviours during writing, the quality of writing products, the development of L2 writing skills, and the task effects on collaboration (Kost, 2011; Li, 2012). However, limited attention has been paid to how students collaborate during collaborative writing and the impact of their collaboration approaches on learning (Li, 2012; Mutwarasibo, 2013; Roussinos \& Jimoyiannis, 2013). Considering that the nature of the collaboration process is closely associated with the quality of student writing performance and learning (Li, 2014; Storch, 2011), it is important to understand how students approach collaboration during wiki-based collaborative writing and how their collaboration approaches affect learning. This study aimed at furthering understanding on this issue through analysing a 
group of Chinese university EFL students' collaboration patterns during wiki-based collaborative writing projects and the relationship between their collaboration patterns and their perception of learning.

\section{Literature review}

\section{Learning through wiki-based collaborative writing}

Both Piagetian socio-cognitive conflict and Vygotskian collective scaffolding lend support to collaborative learning. In line with Piagetian cognitive development theory, collaboration facilitates learning in that social interactions generate cognitive conflict to induce disequilibrium within participants; this in turn, stimulates the reconstruction of conceptual structures and understanding. In Vygotskian sociocultural theory, collaboration facilitates learning by enabling the collective construction of knowledge that individual endeavors cannot provide. When it comes to writing, collaboration further fosters reflective and collaborative talk about language, a greater awareness and understanding of audience, and experience with diverse roles in writing that are not available in solitary writing (Bruffee, 1993; Swain, 2010; Weissberg, 2006). Empirical studies have shown that collaborative writing leads to greater deliberations about language choices, generates more accurate texts than individual writing, and promotes not only writing-skill development but language learning in general (Storch, 2011).

In the last decade, research has increasingly focused on collaborative writing mediated by technological platforms such as wikis, as their supportive features let students both contribute to and engage with each other's contributions. Studies have reported that while L2 learners tend to prefer writing individually, they generally regard their wiki-based collaborative writing experience as beneficial (Chao \& Lo, 2011; Ducate, Anderson, \& Moreno, 2011; Kost, 2011). As wikis have been hypothesised to encourage students' contributions and interactions, researchers are particularly interested in students' interaction patterns during wiki-based collaborative writing. Studies have found that learners tend to make more meaning-focused contributions and changes during wiki-based collaborative writing (Arnold, Ducate, \& Kost, 2009; Kessler, 2009; Mak \& Coniam, 2008), and that learners' willingness to engage with each other's contributions and the nature of the engagement are influenced by various factors such as the size and composition of the groups and the type of task (Storch, 2013). A limited number of studies have examined the group dynamics during online collaborative writing, and how different patterns of collaboration relate to student perceptions and learning (Bradley et al., 2010; Li \& Zhu, 2013).

\section{The nature of collaboration in wiki-based collaborative writing}

Researchers have tried to conceptualise the nature of students' collaboration during collaborative writing. According to Saunders (1989), collaboration could take place at different phases of writing, thus forming different approaches to collaboration: at all phases of writing (co-writing, where students collaborate throughout the planning, composing, revising and editing stages of writing); at planning and composition only (co-publishing, where students divide up the work and each is in charge of one part of the text); and revising or editing only (co-responding and co-editing respectively). Storch (2002) conceptualised the interaction patterns and power relationships during collaboration, drawing on Damon and Phelps's (1989) two dimensions of dyadic interaction patterns. The two dimensions are equality (i.e., the distribution of individual contributions to, and controls over, decision-making and writing) and mutuality (i.e., the degree of engagement with each other's contributions and connected discourse). Storch (2002) categorised four collaboration profiles with varying degrees of equality and mutuality: collaborative, dominant/dominant, dominant/passive, and expert/novice. The first two denote high to moderate levels of equality, with all team members actively involved in the writing process and contributing equally to the final product. The collaborative profile entails joint decision-making and consensus-seeking, whereas the dominant/dominant profile most often involves disagreement with each other's contributions. The last two profiles often involve one member taking over primary control of the writing process. In the expert/novice profile the dominant member invites teammates' contributions. In the dominant/passive profile the dominant member elicits little contribution from the team members. Considering that collaboration mediated by technologies often involves distant interaction, Lowry and colleagues (2004) categorised approaches to collaborative writing on the wiki platforms in terms of the division of labour and the degree of coordination during the writing. Their first category of collaborative writing involves no labour division and limited coordination, and includes two strategies: single-author writing, where one member does the writing for the others; and sequential single writing, where the members write in turns, continuing from the previous member's 
writing. A second type involves a clear division of labour and a high degree of coordination. Either the collaborative writing output is divided into discrete units and each member is in charge of one unit (parallel writing - horizontal division), or the collaborative writing task is divided into different roles such as writers, editors or reviewers, and each member takes on one role (parallel writing - stratified division). A third category is reactive writing, where members collaborate on a writing piece in real time and coordinate the writing process on the go. Despite the different dimensions and terms scholars have adopted to conceptualise the nature of collaboration during writing, these conceptualisations more or less converge on the two dimensions of interaction patterns proposed by Damon and Phelps (1989) at different phases of the collaborative writing task: the nature and amount of group members' contributions to the writing; and the nature and amount of group members' engagement with each other's contributions.

Researchers have also examined students' perceived and actual collaboration behaviours during wiki-based collaborative writing. Interviewing 15 university students on their perceptions of online collaborative writing, Limbu and Markauskaite (2015) found that the participants tended to perceive online collaborative writing tasks more as opportunities to demonstrate what they already knew, rather than as opportunities for learning. Thus the participants inclined towards dividing up the writing tasks and coordinating individual contributions or combining individual strengths for better writing products. Analysing students' actual collaboration behaviours during the writing tasks, Oh (2014) found that when the 16 Korean undergraduate participants in her study collaborated on English academic essays, they employed combined strategies of parallel writing - horizontal division and parallel writing - stratification division. All groups divided the academic essay into several sections for individual responsibility. The author thus concluded that the participants tended to perceive the online collaborative writing task as one that is easily segmented and distributed among the members. Bradley, Lindström, and Rystedt (2010) examined 25 groups of university students' collaboration patterns when co-constructing texts on a wiki, in groups of two or three, and found that students displayed three types of collaboration: no visible cooperation or collaboration (the whole text was uploaded by one member and untouched by the other members), cooperation (members worked in parallel as exhibited in individuals' postings of different sections), and collaboration (members worked together to produce the text as exhibited in intertwined postings among the members across sections). The authors found that 10 groups displayed either a no visible cooperation/collaboration pattern or a cooperation pattern. Roussinos and Jimoyiannis (2013) studied 47 graduate students working in nine groups on wikibased collaborative projects, focusing on the participation patterns and learning presence. The authors identified four patterns of collaboration: low visible interaction, which is characterised by one or two individuals contributing all the texts and few message exchanges among the group members; low collaboration, where group members work on their individual parts and exhibit limited interaction and collaborative creation of the content; moderate collaboration, where most members contribute a significant amount; and high collaboration, where group members exhibit equal amounts of contributions and joint construction of the content. They found that only three groups displayed a high collaboration pattern. Sormunen, Tanni, Alamettättä and Heinström (2014) similarly found that the dominant strategy Finnish secondary-school students adopted during source-based collaborative writing was cooperation in the form of labour division during information searching and writing and the compilation of individual works into a coherent whole at the end.

Current research on the nature of collaboration in wiki-based collaborative writing suggests that students may demonstrate different collaboration patterns when engaging in wiki-based collaborative writing, and that effective collaboration among students cannot be assumed (Shimazoe \& Aldrich, 2010; Storch, 2005). At the same time, scholars have hypothesised that different collaboration patterns may have different impacts on students' writing performance and learning (Saunders, 1989; Storch, 2002). For instance, Lowry and colleagues (2004) claimed that different collaboration approaches offer different benefits and may suit different collaborative writing tasks and group sizes. Thus, researchers call for studies to understand the relationships between collaboration strategies and learning outcomes (Li, 2012; Li \& Zhu, 2013; Mutwarasibo, 2013; Oh, 2014; Roussinos \& Jimoyiannis, 2013).

\section{The nature of collaboration and learning}

Researchers have started to explore the potential association between collaboration patterns and students' perceptions of wiki-based collaboration. Li and Zhu (2013) analysed nine Chinese EFL students' performance during three collaborative essay-writing sessions. The authors found that the three groups of learners demonstrated three interaction patterns: collectively contributing/mutually supportive (no obvious 
expert, equal contribution and high level of engagement with each other's contributions), authoritative/responsive (one person serving as the expert, but engaging with other members' contributions), and dominant/withdrawn (clear expert, little interaction among the team members and limited engagement with each other's contributions). The authors found that the collectively contributing/mutually supportive group and the authoritative/responsive group perceived greater learning opportunities in wiki-based collaborative writing than the dominant/withdrawn group. The authors concluded that mutuality might have mattered more than equality in enhancing students' perceived learning. Li (2014) followed 12 ESL graduate students' performance when working in groups of three on two collaborative writing tasks: a research proposal and an annotated bibliography. The author found that the group that displayed an expert/novice pattern had the most positive perceptions of wiki-based collaborative writing. The author attributed this group's positive perceptions to a high degree of mutuality and positive emotions among members during collaboration. The study further found that the group that displayed a cooperation-in-parallel pattern also perceived wiki-based collaborative writing positively due to their high level of equality, despite the medium to low degree of mutuality. In contrast, the group that demonstrated a dominant-defensive pattern reported the least positive reflections on the experience. The author concluded that high mutuality and/or equality, or an even sharing of workload, is associated with positive perceptions of the collaborative learning experience, and that this association is mediated by the emotional intersubjectivity induced by different interaction patterns.

Thus, current research suggests a potential association between collaboration patterns and students' perceptions of learning from collaborative writing. However, there is limited understanding of how collaboration patterns that vary along the equality and mutuality dimensions might affect learning opportunities in wiki-based collaborative writing. Given the paucity of empirical studies on this issue and the fact that current studies are all based on small sample sizes, more studies are needed to delve deeper into the interaction between collaboration patterns and students' learning from collaborative writing. This study intended to extend understanding of this issue through examining the nature of student collaboration during collaborative writing when effective collaboration was actively promoted, and examine how the students' collaboration patterns affected collaborative learning outcomes. Two research questions were addressed in this study:

a) How did students collaborate during collaborative essay writing?

b) How was the nature of collaboration related to students' perception of learning?

\section{Methodology}

The study adopted a mixed-method design, gathering both quantitative and qualitative data. It triangulated the analysis of the survey data with the content analysis of the interview responses and the archived student performance data on wiki pages to shed light on the two research questions.

\section{Context of the research}

The study was conducted in a 16-week introductory university writing course that introduced students to basic genres and writing techniques. The students were scheduled to do three collaborative essay-writing projects in groups of four or five.

All three writing projects were argumentative essays on the topics: "University education is the most important factor of success in life"; "Is urbanisation making our life better?"; and "Some employers consider social skills as important as good qualification for success in job. To what extent do you agree or disagree?” The three projects were graded assignments. The students were given no word limit and were instructed to work with team members to come up with the best piece their teams could produce collaboratively outside the class. Each project lasted 3 weeks. Wikispaces was used as the online collaborative-writing platform. Students were randomly assigned to different groups, and the group formation remained the same throughout the three projects. Students could edit only their group page, but could view the pages of the other groups.

Considering that lack of collaboration is a common problem during collaborative writing and that students need support for collaboration during such projects, training mechanisms were built in. Training materials on how to write well, how to collaborate, and how to learn through collaboration were hosted on the wiki 
site in the participants' native language in the form of textual explanations accompanied with audiovisual examples. Some online writing tools such as an online dictionary, a grammar checker, and model banks were also provided. The "How to Write Well" page discussed the different stages of writing; planning, writing, revising and editing. It highlighted the strategies to use and issues to pay attention to at each stage. The "How to Collaborate" page included discussions on features of good collaboration at each stage of writing; an introduction to the different roles (cognitive leader, metacognitive leader, language leader, socio-emotional leader) team members could play during collaborative work, with sample scripts for each role; suggestions on two possible collaboration models to highlight the active involvement of all team members at all stages of writing (Model 1: co-planning, collaborative co-writing, co-revising and coediting; Model 2: co-planning, cooperative co-writing, co-revising and co-editing); and tips on how to revise collaboratively. The page also included a video introduction of tools embedded within wikispaces (e.g., discussion forum, comments, archived works) that could support collaboration, and it provided tips on how to use them. The "How to Learn through Collaboration" page included discussions on what to learn through collaborative writing and how to maximise opportunities to learn from peers when doing collaborative writing projects. Figure 1 provides a snapshot of the training materials.

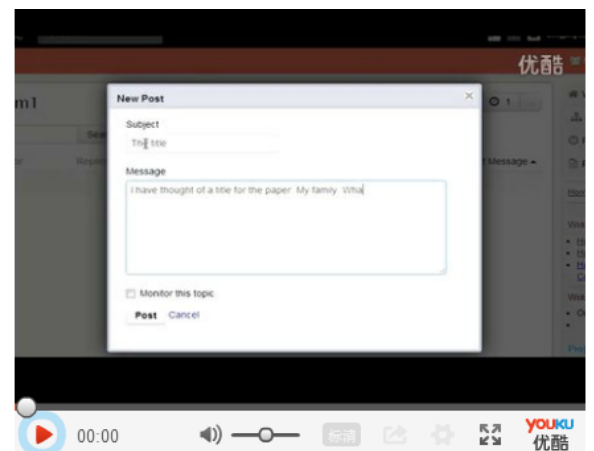

该合作写作网站中有几个工具可以帮助小组更好地合作:

discussion forum: 积极使用discussion forum 在写作的各个岎段, 提出问题, 建议, 讨论, 达成一致。所以每次在进到网站进行写作前, 应 先到discussion forum着看小组成员是否提出了新的问题和讨论义项

comment: 这个工具在进到edit版面后，可以看到。积极使用comment的功能，对当前的内容提出问题，建议，或提醒小组成员你所做的修改 以及修改的理由

- history: history显示到目前为止, 所有小组成员对该页的修改。点击'compare', 你可以看到具体修改的部分。思考为什么组员做了这些修 改, 这些修改有没有道理

合作写作中的角色分T

每个小组成员在合作写作中都应承担一个角色。角色的分工如下图所示:
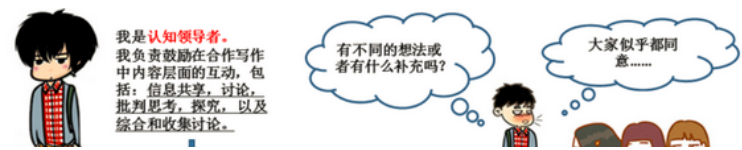

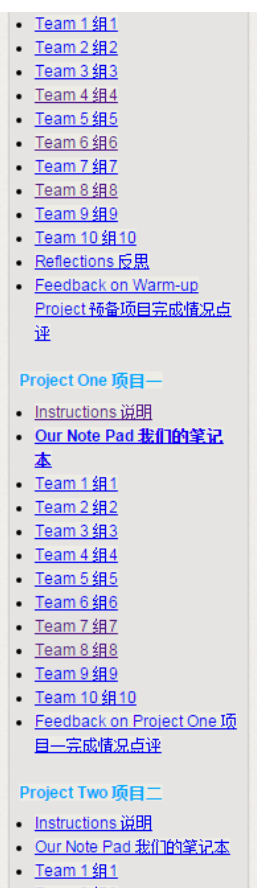

Figure 1. Example of online writing tool: “How to Collaborate” page

A page called "Our Note Pad" was included in the wiki site for students to input useful words, phrases and sentences, tips about writing, and useful resources they had picked up during the collaborative writing projects. The instructor led the students through the training materials prior to the first collaborative project and encouraged them to use the tips provided in the online training materials to enhance their collaborative writing experience. Figure 2 shows the wikipage layout. To further encourage student collaboration, the quality of group collaboration was weighted at $20 \%$ of the final grade. 


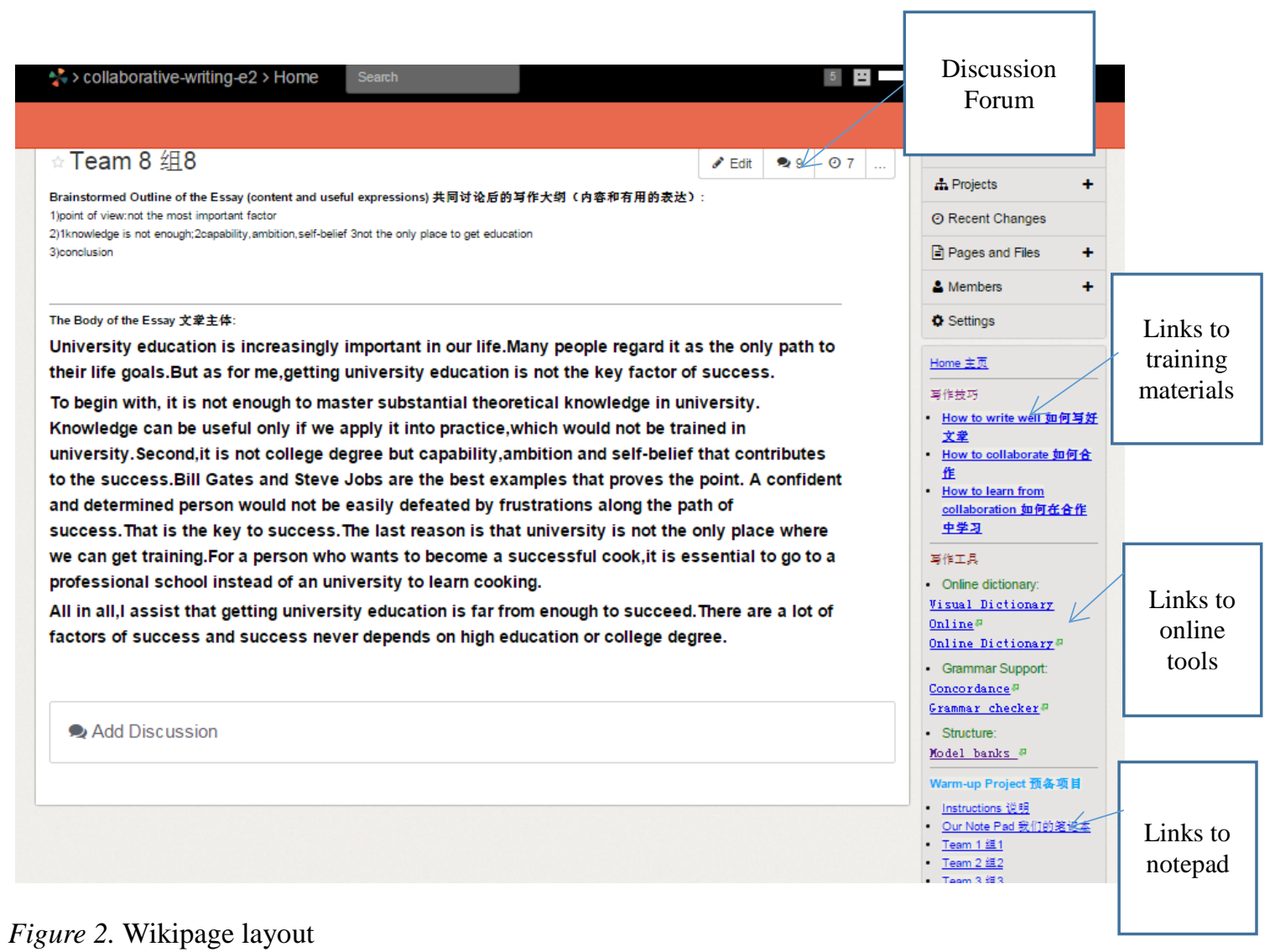

The instructor gave an introduction to the collaborative writing projects and the wiki site at the beginning of the semester. A practice writing project, a collaborative creative writing exercise, familiarised students with collaborative writing on wikispaces. Afterwards, students were assigned the three collaborative writing projects, due throughout the semester. In the instructions for each project, students were reminded of the key collaboration steps, and tips and tools at each of the four writing stages, and they were instructed to post the group's essay outline on their wiki page before starting their composition.

\section{Participants}

The participants were second-year undergraduate students in two writing classes taught by the same instructor, specialising in business and economics in a metropolitan city in China. The participants were international business English majors; they had been studying English for 10 or 11 years and were of intermediate to intermediate-high proficiency. In the two classes there were a total of 113 students, and 105 volunteered to participate in the study (Class One: $N=52$, males $=11$, females $=41$; Class Two: $N=53$, males $=10$, females $=43$ ). The students were formed into 22 groups, most of which had 5 team members. After deleting two groups (one group did not do the collaborative writing projects as instructed, and another group demonstrated an inconsistent collaboration pattern across the three writing projects and thus it was difficult to categorise the group's collaboration approach), 20 groups with a total of 95 students were included in the final analysis of the study. The participants had low self-efficacy in their English writing abilities, and did not enjoy English writing. They rated their English proficiency and English writing skills quite low, however, they had stronger confidence in their ability to collaborate and learn through collaboration. Their attitudes towards collaborative writing were slightly on the negative side $(M=3.81$, $S D=0.88)$ (Table 1$)$. 
Table 1

Participants' pre-survey responses on their writing and collaboration abilities

\begin{tabular}{llll}
\hline & $N$ & $M$ & $S D$ \\
\hline English proficiency & $90^{*}$ & 3.39 & 0.77 \\
Writing ability & 90 & 3.17 & 0.97 \\
Writing enjoyment & 90 & 3.20 & 0.91 \\
Writing efficacy & 90 & 2.90 & 0.90 \\
Collaboration efficacy & 90 & 3.99 & 0.75 \\
Collaborative learning efficacy & 90 & 4.11 & 0.72 \\
Attitude to collaborative writing & 90 & 3.81 & 0.88 \\
\hline
\end{tabular}

* Only 90 of the 95 study participants completed the pre-survey.

\section{Data sources}

Prior to the study, the participants were surveyed on their perceptions and attitudes towards English writing and collaborative learning using a 6-point Likert scale ( 1 = strongly disagree and $6=$ strongly agree $)$. The participants were also asked to rate their English proficiency and English writing abilities on a 6-point Likert scale $(1=$ very poor and $6=$ very good $)$. At the end of the collaborative writing projects, the participants were surveyed on their enjoyment of two items: "I enjoyed learning English through collaborating with others on writing projects", and "I enjoyed collaborating with my teammates on the collaborative writing projects we did this semester" $(\alpha=0.83)$. They were surveyed on their attitudes towards two items: "I feel I learn more from writing alone than from writing collaborating with others", and "Doing collaborative writing projects is totally a waste of time" $(\alpha=0.60)$. They were also surveyed about their perceived learning from three items: "My English improved through doing the collaborative writing projects with my teammates", "My ability to write English essays increased through doing the collaborative writing”, "I am getting more confident with my ability of writing English essay after doing the collaborative writing projects" $(\alpha=0.92)$. The survey items were constructed by the researchers with reference to prior studies on students' perceptions of wiki-based collaborative writing (Arnold et al., 2009; Chao \& Lo, 2011; Ducate et al., 2011; Kost, 2011; Lee, 2010). The post-survey also included several openended questions to elicit participants' responses on the collaboration approaches adopted in their respective groups: things they learned through the projects and how they could have collaborated better. All the questions were in Mandarin, the participants' native language. The survey items were pilot tested on a group of undergraduate students of similar backgrounds to those who participated in the study, and revisions were made to avoid potential misinterpretations of the survey items. Both surveys were administered in class by the second author.

Follow-up focus-group interviews were conducted with students from four groups (19 participants in total). The groups were randomly selected from the 20 groups of participants included in this study. The participants, 15 female and 4 male, took part in the interview on a voluntary basis. The interviews focused on what the participants liked about the collaborative writing projects, the challenges they encountered doing the projects, and how collaborative writing projects helped or did not help with the development of English learning and writing ability. The second author conducted the focus-group interviews, in groups of four or five, in the participants' native language, Mandarin. Each group interview lasted for approximately 20 minutes.

The archived performance data of the participants from throughout the three projects also served as a major data source to understand groups' collaboration approaches and students' peer-revision behaviours. The archived performance data included students' discussion-forum posts, comments and archived changes to the page.

\section{Data analyses}

To understand participants' collaboration approaches during the three writing projects, the archived performance data, particularly the archived changes to the group wiki pages, were used to determine participants' collaboration patterns. The collaboration patterns were categorised with reference to the division of labour and the level of coordination as well as the two critical dimensions of interaction 
(mutuality and equality) (Damon \& Phelps, 1989; Li \& Zhu, 2013; Lowry et al., 2004). Group performance on each collaborative writing project was categorised first, then the consistent collaboration patterns across the three projects (defined as the patterns adopted by the group for two or three projects) were used to determine each group's collaboration approach. The participants' reported collaboration approaches in their post-survey responses were also used to corroborate and supplement the categorisation of collaboration patterns.

To understand the relationship between group collaboration patterns and students' perceptions, post-survey responses on their enjoyment of, attitudes about and perceived learning from the collaborative writing projects were compared across different collaboration patterns. Participants' open-ended responses in the post-survey on what they learned through the projects were compared across different collaboration patterns to reveal possible differences in learning among groups that adopted different patterns. The interview responses and students' peer-revision behaviours were analysed to shed light on how collaborative patterns might have affected learning. Students' archived changes made on the group page after the first posting were categorised into surface changes and text-based changes following Faigley and Witte's (1981) peerrevision coding scheme. Surface changes included both formal changes (including conventional copyediting changes such as tense, modality, subject-verb agreement, part of speech), and meaningpreserving changes (including changes that paraphrased the text without altering the meaning of the text). Text-based changes included both micro-meaning changes and macro-meaning changes that altered the meaning of the text. The proportions of surface changes and text-based changes under different collaboration styles were then compared.

\section{Findings}

\section{The nature of collaboration}

The majority of the participants reported engaging actively in the co-planning stage. In their post-survey responses on how their groups collaborated, 18 out of the 20 groups reported discussing and deciding on the outlines of their essays together, prior to composition. They reported discussing the main arguments and the logical sequencing of these arguments among the team members either face-to-face or via instant messenger or the embedded discussion forum within wikispaces. For instance, one participant reported:

We first discussed our positions and decided on the main arguments. Then we divided the essay into different paragraphs and determined the argument within each paragraph including the main points and major evidence.

Some variations existed in groups' approaches to co-planning. Most of the groups brainstormed ideas, discussed the ideas and posted the agreed-on outline on the wiki pages. A few groups discussed the initial work of some team members. For instance, one group had a volunteer draft the outline first, and the other students commented on the outline and co-constructed the final outline. Another group had each team member draft their own version of the essay, then the team members discussed and decided on the outline of their collaborative work based on a review of the drafts.

The analysis of the archived discussion forum posts, comments and wikipage changes suggested that the participants exhibited three styles of collaboration during the composition and revision stages: Style (1) single composing and interactive revising; Style (2) parallel composing with concurrent interactive revising; and Style (3) parallel composing with limited interactive revising. Single composing and interactive revising referred to a collaboration style where the group members designated one person to draft the essay and the rest of the group took turns to revise and edit the draft. Eleven out of the 20 groups primarily (in at least two of the projects) adopted the single composing and interactive revising collaboration style (Style 1). Parallel composing with concurrent interactive revising (Style 2) was evident in the groups that placed a different group member in charge of each part of the essay, but where the majority of the group members were involved in revising. This included either revising the content that had been uploaded previously before posting their own parts or revising and editing the content after the whole draft was completed. Five of the 20 groups primarily adopted this approach. Parallel composing with limited interactive revising (Style 3) was the case when each group member was in charge of one section of the essay, but either only one member or none was involved in revising. Four groups primarily adopted this approach, two groups having only one member in charge of the revising, and two having no revision 
activities going on at all.

Thus, despite an instructional design intended to encourage and support a collaborative approach to the group writing projects, the participants took different approaches to collaboration. The participants demonstrated a greater level of collaboration at the planning and revision phases, but approached the composition phase in a more designating or cooperative manner.

\section{Relationship between collaboration style and perceived learning}

Table 2 shows that the participants across the three collaboration styles did not show significant differences in their attitudes to or confidence in writing and collaboration prior to the collaborative writing projects. However, participants across the three different collaboration styles did show significant differences in their enjoyment from the projects, and in their attitudes towards the value of collaborative writing in general as shown in Table 3.

Table 2

Participants' pre-survey responses on their writing and collaboration abilities by collaboration styles

\begin{tabular}{lllllll}
\hline & & $N$ & $M$ & $S D$ & $\chi^{2}$ & $p$ \\
\hline English proficiency & Style 1 & 50 & 3.28 & 0.81 & 1.80 & 0.41 \\
& Style 2 & 24 & 3.5 & 0.66 & & \\
& Style 3 & 16 & 3.56 & 0.81 & & 0.90 \\
\hline Writing ability & Style 1 & 50 & 3.12 & 1.06 & 0.20 & \\
& Style 2 & 24 & 3.25 & 0.79 & & \\
& Style 3 & 16 & 3.19 & 0.98 & & \\
\hline Writing enjoyment & Style 1 & 50 & 3.25 & 0.96 & 1.90 & 0.39 \\
& Style 2 & 24 & 3.23 & 0.81 & & \\
\hline Writing efficacy & Style 3 & 16 & 3.00 & 0.88 & & 0.68 \\
& Style 1 & 50 & 2.83 & 0.92 & 0.77 & \\
& Style 2 & 24 & 3.08 & 0.80 & & \\
\hline Collaboration efficacy & Style 3 & 16 & 2.94 & 1.05 & & \\
& Style 1 & 50 & 3.85 & 0.75 & 1.83 & \\
& Style 2 & 24 & 4.17 & 0.67 & & \\
\hline Collaborative learning & Style 3 & 16 & 4.19 & 0.81 & & \\
efficacy & Style 1 & 50 & 4.03 & 0.63 & 2.95 & 0.23 \\
& Style 2 & 24 & 4.10 & 0.76 & & \\
\hline Attitude to collaborative & Style 3 & 16 & 4.35 & 0.88 & & 0.12 \\
writing & Style 1 & 50 & 3.63 & 0.87 & 4.21 & \\
& Style 2 & 24 & 4.01 & 0.76 & & \\
\hline
\end{tabular}

Note: Style 1 - single composing/co-revising; Style 2 - parallel composing/concurrent co-revising; Style 3 - parallel composing/limited co-revising

Perceived enjoyment

The responses from the participants in Styles 2 and 3 were generally positive, with those in Style 2 reporting the highest level of enjoyment $(M=4.46, S D=.72)$. The participants in Style 1 reported the lowest level of enjoyment with the projects, with their responses slightly on the negative side $(M=3.92 ; S D=.93)$. A non-parametric one-way Kruskal-Wallis test on students' level of enjoyment showed that the differences across the styles were statistically significant $\left(\chi^{2}=6.81, p=.03\right)$, and that a significant difference lay between Style 2 and Style $1(t=2.50, p=.04)$. 
Table 3

Perceived learning across the different collaboration styles

\begin{tabular}{lllllll}
\hline & & $N$ & $M$ & $S D$ & $\chi^{2}$ & $p$ \\
\hline Enjoyment of the projects & Style 1 & 54 & 3.92 & .93 & $6.81^{*}$ & .03 \\
& Style 2 & 25 & 4.46 & .72 & & \\
& Style 3 & 16 & 4.28 & .77 & & \\
\hline Attitudes to collaborative writing & Style 1 & 54 & 3.44 & .54 & $7.16^{*}$ & .03 \\
& Style 2 & 25 & 2.88 & .97 & & \\
& Style 3 & 16 & 3.24 & .87 & & \\
\hline Learning out of the projects & Style 1 & 54 & 4.27 & .53 & 4.40 & .11 \\
& Style 2 & 25 & 4.13 & .57 & & \\
& Style 3 & 16 & 3.97 & .86 & & \\
& & & & &
\end{tabular}

Note: Style 1 - single composing/co-revising; Style 2 - parallel composing/concurrent co-revising;

Style 3 - parallel composing/limited co-revising.

* represented statistically significant results at $\mathrm{p}<.05$

This finding seems to be associated with the equality of contribution across the three collaboration styles: Styles 2 and 3 involved a division of labour where each group member was in charge of part of the composing and/or revising, and thus had a higher level of equality. In contrast, Style 1 had only one or two members in charge of the composing, and thus had a lower level of equality. The analysis of group peer contributions also suggested a profile of unequal participation among the group members in Style 1 (around $63 \%$ of the time, one group member contributed more than half of the peer changes), whereas more than half of the peer changes were contributed by one group member, this was only $16 \%$ in groups using Style 2 , and $39 \%$ in groups using Style 3. To examine whether the equality of contribution was the underlying reason behind the differences in perceived enjoyment, we combined Style 2 and Style 3 (high equality) together and compared the combined group against Style 1 (low equality). The Mann-Whitney U test showed that participants in the equal-contribution collaboration style reported significantly greater positive perceptions of enjoying the projects $(U=2.52, p=.01)$.

Table 4

Perception of learning along the equality dimension

\begin{tabular}{lllllll}
\hline & $N$ & $M$ & $S D$ & $U$ & $p$ \\
\hline Enjoyment of the projects & $\begin{array}{l}\text { Equal contribution } \\
\text { (Style 2 + Style 3) } \\
\text { Unequal contribution } \\
\text { (Style 1) }\end{array}$ & 54 & 4.39 & .74 & $2.52 *$ & .01 \\
\hline $\begin{array}{l}\text { Learning out of the } \\
\text { projects }\end{array}$ & $\begin{array}{l}\text { Equal contribution } \\
\text { (Style 2 + Style 3) } \\
\text { Unequal contribution } \\
\text { (Style 1) }\end{array}$ & 41 & 3.97 & .86 & & \\
\hline $\begin{array}{l}\text { Attitudes to collaborative } \\
\text { writing }\end{array}$ & $\begin{array}{l}\text { Equal contribution } \\
\text { (Style 2 + Style 3) } \\
\text { Unequal contribution } \\
\text { (Style 1) }\end{array}$ & 54 & 3.10 & .87 & 0.95 & .34 \\
\hline
\end{tabular}

Note: * represented statistically significant results at $\mathrm{p}<.05$

The low level of equal contribution was perceived negatively by the participants using Style 1 . In their responses to the open-ended question on how their team could collaborate better, some expressed the wish for equal contribution, "We should involve each member to participate and divide the work so that no one is left out”; “The teacher should punish individuals who don't take responsibility so that everyone participates with a greater sense of responsibility"; "We need a more fine-tuned division of labour and a greater level of discussion prior to writing”. In contrast, none of the participants from Styles 2 and 3 mentioned this issue in their responses, and their comments focused primarily on the need to enhance the level of communication and to seek better approaches to enhancing communication. The participants' interview responses suggest some potential reasons behind the association between the low level of equality in collaboration and lower perceived enjoyment of the projects. One participant from Style 1 commented on the lack of the sense of collaboration: 
To tell the truth, although it's collaborative writing in name, it was usually one person doing the composing and the others revising. Most often we didn’t treat the revision seriously and there was not much sense of collaboration at all.

Another participant echoed, "We did group discussion and then one person was in charge of writing. It didn't give the feeling that everyone is actively engaged in the process.” The participants also remarked on the lack of the sense of ownership in Style 1. For instance, one participant said, "For a draft that was already in shape, normally we wouldn't make major changes. Thus, you wouldn't have the sense of ownership even after you made the revisions." Thus, the high level of coordination involved in equal contribution, as in Styles 2 and 3, might have given students a greater sense of belonging and ownership, and thus a perception of greater enjoyment.

\section{Perceived learning}

In their survey responses regarding the perceived efficacy of collaborative writing in enhancing general English proficiency and English writing confidence and skills, the participants using Styles $2(M=4.27$, $S D=.53)$ and $3(M=4.13, S D=.57)$ gave more positive responses than the participants using Style $1(M$ $=3.97, S D=.86)$. Although the non-parametric one-way Kruskal-Wallis test did not show statistically significant differences among the styles $\left(\chi^{2}=4.40, p=.11\right)$, the more-positive perceptions among the participants in Styles 2 and 3 (which represented higher levels of equality) seemed to suggest a possible effect of the equality of contribution on perceived learning (Table 3). We again combined Styles 2 and 3 together and compared the combined group against Style 1 to test this potential effect. The Mann-Whitney $\mathrm{U}$ test on the combined categories of Styles 2 and 3 (high equality) against Style 1(low equality) did show significantly greater positive perceptions towards learning among the groups with the equal-contribution collaboration style as compared to those with the unequal-contribution style $(U=1.20, p=.046)$ (Table 3$)$. Furthermore, the participants' responses to the open-ended survey question on what they had learned from doing the collaborative writing projects also suggested a potential advantage of Styles 2 and 3 for learning. A greater proportion of the participants using Styles 2 and 3 reported learning new phrases and sentence structures, picking up new ideas and acquiring writing techniques and text-organisation skills from doing the projects as compared to the participants using Style 1 (Table 5).

Table 5

Reported learning from doing the collaborative writing project

\begin{tabular}{lllll} 
& $\begin{array}{l}\text { New phrases and sentence } \\
\text { structures }\end{array}$ & $\begin{array}{l}\text { New } \\
\text { ideas }\end{array}$ & $\begin{array}{l}\text { Writing techniques and text } \\
\text { organisation }\end{array}$ & $\begin{array}{l}\text { How to } \\
\text { collaborate }\end{array}$ \\
\hline Style 1 & $38 \%$ & $8 \%$ & $20 \%$ & $38 \%$ \\
Style 2 & $35 \%$ & $30 \%$ & $38 \%$ & $43 \%$ \\
Style 3 & $27 \%$ & $20 \%$ & $13 \%$ & $47 \%$ \\
\hline
\end{tabular}

We further found that the nature of the contribution induced by different collaboration styles might have contributed to the difference in perceived learning across the collaboration styles. For one thing, the nature of the contributions induced by different collaboration styles might have affected the participants' attention to their peers' contributions. The requirement of relatively more equal contribution to the composition in Styles 2 and 3 placed greater demands on the level of coordination across their contributions. One participant commented that the equal-contribution collaboration style made her pay more attention to the texts posted by her peers, "When I wrote my part, I needed to read what others had written before so that I could connect better with what they'd written previously. Thus, I would pay more attention to what others had posted." In contrast, in Style 1, one or two group members were the sole contributor(s) of the draft and the rest just revised it, which gave little incentive for them to revisit the group page to see other peers' changes once they were done with their individual round of revision. As one participant pointed out:

In our group we had one person drafting the essay and the rest of us revising it in turn. This kind of labour division was very discrete. Normally we never or seldom got back to view the page once we'd finished our turns of revision.

For another, the nature of contributions induced by different collaboration styles might have afforded different levels of learning opportunities. When analysing the changes participants made to the initial postings on the group pages, we found that the changes made by the participants using Style 2 were the 
most balanced, with about the same proportion of surface changes (47\%) and text-based changes (53\%). In contrast, the changes by the participants using Styles 1 and 3 were heavily biased: Style 1 towards surface changes (80\% of the total revisions); and Style 3 towards text-based changes ( $82 \%$ of the total revisions) (Table 6). Thus Style 2 afforded more opportunities for learning, as it provided learners with opportunities to learn both at the language level and at the content-organisation level. Although Styles 1 and 3 were both biased, the participants seemed to prefer peer help with content over that for language mechanics. As one participant from Style 1 pointed out, "I feel that we mainly corrected each other's language errors. However, for writing, what's more important is the content." Another participant echoed her point of view that collaborative writing lent more to learning in terms of idea-generation and organisation than language:

During collaborative writing, we can pick up good ideas from each other. But in terms of language, you won't change that easily simply because your peer corrected it for you. You would still make the same errors the next time around.

Style 1 was more likely to induce peer revisions on language, "When others drafted the essay, the line of arguments was fixed. There really was not much to change.” Thus, the greater demands on the coordination between the contents and the more opportunities for participants to see peer contributions to the content enhanced the perceived learning among the participants in Styles 2 and 3.

Table 6

Types of peer changes across the three collaboration styles

\begin{tabular}{lll} 
& Text-based changes & Surface changes \\
\hline Style 1 & $20 \%$ & $80 \%$ \\
Style 2 & $53 \%$ & $47 \%$ \\
Style 3 & $82 \%$ & $18 \%$ \\
\hline
\end{tabular}

Attitudes to collaborative writing

The participants using all three collaboration styles reported positive attitudes towards collaborative writing activities, as the averages of their survey responses reflecting negative perceptions all fell below 4 . They did acknowledge the benefits of collaborative writing, feeling that collaborative writing created peer learning opportunities (e.g., "We could learn from each other and learn from each other's strengths"). This peer learning helped with both idea generation and language accuracy (e.g., "We can hear each other's opinions and enrich our perspectives on an issue"; "When we wrote together, we could point out each other's errors and get better ideas"). They also felt that collaborative writing raised their language awareness (e.g., "When we wrote collaboratively”, "I was more careful with the words I used”).

Despite the participants' generally positive attitudes towards collaborative writing activities, there were differences in their attitudes across the three styles. The participants using Style 2 reported the leastnegative attitudes $(M=2.88, S D=.97)$, and those using Style 3 reported the most-negative attitudes $(M=$ $3.44, S D=.54)$. The differences across the three collaboration styles were statistically significant $\left(\chi^{2}=7.16\right.$, $p=.03)$, and pairwise comparison showed that the difference between Styles 2 and 3 was significant $(t=$ 2.50, $p=.04$ ) (Table 3). Considering that the participants in the three collaboration styles had similar attitudes towards collaborative writing to start with and that the attitudes of those using Style 3 changed from the most-positive at the beginning to the most-negative at the end of the projects, something about Style 3 negatively affected the participants' attitudes to the value of collaborative writing. The differences between Style 3 and the other two styles lay in the lack of collaborative revising and editing. The participants using Style 3 made changes to the collaborative text primarily through adding their individual sections after teammates' contributions, seldom making revisions to each other's contributions. Thus, the level of mutuality at the revising stage might have made some differences here. Styles 1 and 2 had a relatively higher level of mutuality, whereas Style 3 had a low level of mutuality. Although the MannWhitney $U$ test on high mutuality (Styles 1 and 2 combined) and the mutuality (Style 3) did not suggest a significant difference across collaboration styles along this dimension $(U=1.65, p=.10)$ (Table 7), the participants' survey responses from those using Style 3 did indicate negative perceptions of the low level of mutuality. The majority of the participants using Style 3 commented specifically on the necessity of mutual engagement with each other's contributions when responding to the open-ended survey question on how they could have collaborated better: "We need to do peer review", "We need to enhance peer feedback”, "We should set peer revision as an unnegotiable requirement". Thus, the level of mutuality at the revising stage might have affected the participants' perceptions of the value of collaborative writing in 
general.

Table 7

Perception of learning along the mutuality dimension

\begin{tabular}{|c|c|c|c|c|c|c|}
\hline & & $N$ & $M$ & $S D$ & $U$ & $p$ \\
\hline \multirow[t]{2}{*}{ Enjoyment of the projects } & $\begin{array}{l}\text { High mutuality } \\
\text { (Style 1 + Style 2) }\end{array}$ & 76 & 4.08 & .90 & \multirow[t]{2}{*}{0.74} & \multirow[t]{2}{*}{.46} \\
\hline & $\begin{array}{l}\text { Low mutuality } \\
\text { (Style 3) }\end{array}$ & 19 & 4.28 & .77 & & \\
\hline \multirow[t]{2}{*}{ Learning out of the projects } & $\begin{array}{l}\text { High mutuality } \\
\text { (Style } 1+\text { Style 2) }\end{array}$ & 76 & 4.07 & .78 & \multirow[t]{2}{*}{0.48} & \multirow[t]{2}{*}{.64} \\
\hline & $\begin{array}{l}\text { Low mutuality } \\
\text { (Style 3) }\end{array}$ & 19 & 4.13 & .57 & & \\
\hline \multirow[t]{2}{*}{$\begin{array}{l}\text { Attitudes to collaborative } \\
\text { writing }\end{array}$} & $\begin{array}{l}\text { High mutuality } \\
\text { (Style } 1+\text { Style 2) }\end{array}$ & 76 & 3.13 & .91 & \multirow[t]{2}{*}{1.65} & \multirow[t]{2}{*}{.10} \\
\hline & $\begin{array}{l}\text { Low mutuality } \\
\text { (Style 3) }\end{array}$ & 19 & 3.44 & .54 & & \\
\hline
\end{tabular}

\section{Discussion}

This study examined how university EFL learners approached collaborative essay-writing tasks and their perceptions of the learning experience. It found that groups of learners adopted one of three approaches to collaboration: single composing/interactive revision, parallel composing/concurrent interactive revision, or parallel composing/limited interactive revision. It further found that the learners who adopted each collaboration approach perceived the learning experience differently, with those adopting parallel writing with concurrent interactive revision collaboration reporting the most-positive perceptions. These three collaboration styles diverge along Damon and Phelps's (1989) two dimensions of interaction: equality and mutuality. Parallel composing/concurrent interactive revision was characterised by high equality and high mutuality in composing and revising, and was found to be associated with significantly more positive perception of enjoyment of the projects, enhanced writing confidence and skills and attitudes towards collaborative writing in general than the other two styles. This finding confirmed Damon and Phelps's (1989) arguments on the developmental and motivational edge of the high-equality and high-mutuality collaboration approach, and corroborated previous research findings that high equality and high mutuality lead to greater perceived learning opportunities (Li, 2014; Li \& Zhu, 2013; Mutwarasibo, 2013).

This study further found that equality and mutuality might have had different impacts on different learning outcomes. A high level of equality during composition was found to be associated with greater enjoyment of the collaborative writing projects. This association was likely due to the sense of collaboration and ownership that different levels of equality during composing might have induced. A high level of equality during composing was also found to be associated with greater perceived learning due to the balance in language-related and content-related wise changes induced and the learning benefits thereof. High level of mutuality during revision was found to be associated with more-positive attitudes to collaborative writing in general, as revealed in the participants' survey responses, although this different was not significant in the statistical analysis. The research findings differ from those of previous studies highlighting the superiority of mutuality in determining collaborative learning ( $\mathrm{Li}, 2014$; Li \& Zhu, 2013). The discrepancies might be due to the fact that this study focused on the equality and mutuality reflected in the archived composition and revision performance, whereas the previous studies defined the equality and mutuality based on students' discourses in discussion. Thus, this finding suggests that, in the context of collaborative essay writing, a more fine-grained understanding of the effects of equality and mutuality on collaboration might be needed. Equality and mutuality during different phases of collaborative writing might affect different learning outcomes differently, and the effects might be mediated by various factors such as the sense of collaboration and ownership and the nature of peer contribution when using wiki-based collaborative writing in second-language learning.

In this study, all the groups adopted some form of division of labour: some groups adopted a stratified labour division (dividing the labour in terms of different roles: composing, revising etc.), and others adopted a horizontal labour division (dividing the labour in terms of composing different sections of the essay). The finding on the general preference of collaboration through division of labour concurs with the findings from 
previous studies (Limbu \& Markauskaite, 2015; Oh, 2014; Sormunen et al., 2014) that have reported that students tend to consider division of labour to be an efficient way to collaborate (Limbu \& Markauskaite, 2015). However, this study found that different approaches to division of labour might afford different learning opportunities. When students divided the labour in terms of the composition and revision roles, their learning was limited because such labour division often induced predominantly language-level changes, with limited peer changes at the content-generation and organisation levels. Given students' reservations about peer language revisions (Mendoca \& Johnson, 1994; Tsui \& Ng, 2000), a division-oflabour approach may afford limited learning opportunity for language learners. Thus, this study suggests that a combination of horizontal and stratified labour division might be preferable when using wiki-based collaborative writing in second-language learning.

\section{Conclusion}

This study examined how university undergraduate students collaborated during collaborative essay writing and how the nature of their collaboration was associated with their perception of the learning experience. This study found that despite their instructors' encouragement and support, the majority of the students did not demonstrate a collaborative approach to composing, and that the different collaboration approaches these students adopted generated different perceived learning opportunities and experiences. Thus, the study suggests the importance of helping students develop favourable collaboration patterns to maximise the potential of wiki-based collaborative writing for learning. This study did introduce some training and support mechanisms for collaboration, however the training consisted of a one-shot intervention and static materials online. Future training may consider a situated, ongoing approach that incorporates constant reminders from the instructors on using different strategies, and early identification of, and intervention regarding, group collaboration behaviour. Furthermore, this study verified that equality and mutuality are useful dimensions in differentiating the benefits to learning of different collaboration styles, and further found that equality and mutuality might have different impacts on different learning outcomes. Thus, the finding calls for a more fine-grained approach to understanding the effects on learning of equality and mutuality during collaboration. Furthermore, future research may want to examine the affective, social and cognitive effects associated with equality and mutuality at different phases of collaborative writing, as equality and mutuality might carry different effects during the planning phase to those during the composition and revision phases. This study further identified that the approaches to labour division and the nature of peer contribution induced by different collaboration styles might also influence the benefits to learning of different approaches to collaboration in the context of second-language learning. Researchers may want to examine how these associated collaboration variables might affect learning outside of wikibased collaborative writing. In-depth understanding of how different variables relate to the nature of collaboration is critical to enhancing the efficacy of wiki-based collaborative writing for learning.

This study has several limitations. First, the study's discussion on equality and mutuality was mainly based on the analysis of the participants' archived performance in the wiki. The participants' discussions and interactions off the wiki platform were not captured. Thus, the findings on the influences of equality and mutuality were largely constrained to the composition and revision phases. Future studies may want to analyse the learning benefits of equality and mutuality in different phases of writing. Second, the study examined EFL learners' wiki-based collaborative writing on argumentative essay-writing alone, and students' collaboration patterns and their influences on learning might vary when writing different genres. It would be interesting to examine this issue in collaborative second-language writing in different genres. Third, the study was based on a group of EFL learners of Chinese cultural backgrounds, and their beliefs on collaboration and peer feedback might have affected some of the research findings. It would be necessary to examine the same issue in different cultural contexts ( $\mathrm{Li} \& \mathrm{Zhu}, 2013$ ). Despite the limitations, this study enhanced our understanding of the relationship of collaboration patterns and learning by highlighting a fine-tuned view towards the impact of equality and mutuality on learning from collaborative writing, and by raising our attention to other associated factors, such as the type of labour division and the nature of peer contribution, that might affect the learning opportunities in wiki-based collaborative writing in the context of second-language learning.

\section{References}

Arnold, N., Ducate, L., \& Kost, C. (2009). Collaborative writing in wikis: Insights from culture projects in intermediate German classes. In L. Lomicka \& G. Lord (Eds.), The next generation: Social 
networking and online collaboration in foreign language learning (CALICO Monograph Series, Vol 5, pp. 115-144). San Marcos, TX: Texas State University.

Bradley, L., Lindström, B., \& Rystedt, H. (2010). Rationalities of collaboration for language learning in a wiki. ReCALL, 22(2), 247-265. http://dx.doi.org/10.1017/S0958344010000108

Brufee, K. (1993). Collaborative learning: Higher education, interdependence and the authority of knowledge. Baltimore, MD: Johns Hopkins University Press.

Chao, Y. C. J., \& Lo, H. C. (2011). Students' perceptions of wiki-based collaborative writing for learners of English as a foreign language. Interactive Learning Environments, 19(4), 395-411. http://dx.doi.org/10.1080/10494820903298662

Damon, W., \& Phelps, E. (1989). Critical distinctions among three approaches to peer education. International Journal of Educational Research, 13(1), 9-19. http://dx.doi.org/10.1016/08830355(89)90013-X

Dobao, A. F. (2012). Collaborative writing tasks in the L2 classroom: Comparing group, pair, and individual work. Journal of Second Language Writing, 21(1), 40-58. http://dx.doi.org/10.1016/j.jslw.2011.12.002

Ducate, L. C., Anderson, L. L. \& Moreno, N. (2011). Wading through the world of wikis: An analysis of three wiki projects. Foreign Language Annals, 44(3), 493-522. http://dx.doi.org/10.1111/j.19449720.2011.01144.X

Faigley, L., \& Witte, S. (1981). Analyzing revision. College Composition and Communication, 32(4), 400-414. http://dx.doi.org/10.2307/356602

Hodges, C. G. (2002). Learning through collaborative writing. Reading, 36(1), 4-10. http://dx.doi.org/10.1111/1467-9345.00178

Kessler, G. (2009). Student-initiated attention to form in wiki-based collaborative writing. Language Learning \& Technology, 13(1), 79-95.

Kost, C. (2011). Investigating writing strategies and revision behavior in collaborative wiki projects. CALICO Journal, 28(3), 606-620. http://dx.doi.org/10.11139/cj.28.3.606-620

Lee. L. (2010). Exploring wiki-mediated collaborative writing: A case study in an elementary Spanish course. CALICO Journal, 27(2), 260-276. http://dx.doi.org/10.11139/cj.27.2.260-276

Li, M. (2012). Use of wikis in second/foreign language classes: A literature review. CALL-EJ, 13(1), 1735.

Li, M. (2014). Small group interactions in wiki-based collaborative writing in the EAP context (Doctoral dissertation). University of South Florida, USA. Retrieved from http://scholarcommons.usf.edu/cgi/viewcontent.cgi?article=6450\&context=etd.

Li, M., \& Zhu, W. (2013). Patterns of computer-mediated interaction in small writing groups using wikis. Computer Assisted Language Learning, 26(1), 61-82. http://dx.doi.org/10.1080/09588221.2011.631142

Limbu, L., \& Markauskaite, L. (2015). How do learners experience joint writing: University students' conceptions of online collaborative writing tasks and environments. Computers \& Education, 82, 393408. http://dx.doi.org/10.1016/j.compedu.2014.11.024

Lowry, P. B., Curtis, A., \& Lowry, M. R. (2004). Building a taxonomy and nomenclature of collaborative writing to improve interdisciplinary research and practice. Journal of Business Communication, 41(1), 66-99. http://dx.doi.org/10.1177/0021943603259363

Mak, B., \& Coniam, D. (2008). Using wikis to enhance and develop writing skills among secondary school students in Hong Kong. System, 36(3), 437-455. http://dx.doi.org/10.1016/j.system.2008.02.004

Mendonca, C. O., \& Johnson, K. E. (1994). Peer review negotiations: Revision activities in ESL writing instruction. TESOL Quarterly, 28(4), 745-769. http://dx.doi.org/10.2307/3587558

Mutwarasibo, F. (2013). University students' conceptions and practice of collaborative work on writing. International Journal of Higher Education, 2(2), 13-21. http://dx.doi.org/10.5430/ijhe.v2n2p13

Oh, H. (2014). Learners' writing performance, revision behavior, writing strategy, and perception in wikimediated collaborative writing. Multimedia-Assisted Language Learning, 17(2), 176-199.

Nevid, J. S., Pastva, A., \& McClelland, N. (2012). Writing-to-learn assignments in introductory psychology. Is there a learning benefit? Teaching of Psychology, 39(4), 272-275. http://dx.doi.org/10.1177/0098628312456622

Roussinos, D., \& Jimoyiannis, A. (2013). Analysis of students’ participation patterns and learning presence in a wiki-based project. Educational Media International, 50(4), 306-324. http://dx.doi.org/10.1080/09523987.2013.863471

Saunders, W. M (1989). Collaborative writing tasks and peer interaction. International Journal of 
Educational Research, 13(1), 101-112. http://dx.doi.org/10.1016/0883-0355(89)90019-0

Shehadeh, A. (2011). Effects and student perceptions of collaborative writing in L2. Journal of Second Language Writing, 20(4), 286-305. http://dx.doi.org/10.1016/j.jslw.2011.05.010

Shimazoe, J., \& Aldrich, H. (2010). Group work can be gratifying: Understanding \& overcoming resistance to cooperative learning. College Teaching, 58(2), 52-57. http://dx.doi.org/10.1080/87567550903418594

Sormunen, E., Tanni, M., Alamettälä, T., \& Heinström, J. (2014). Students' group work strategies in source-based writing assignments. Journal of the Association for Information Science and Technology, 65(6), 1217-1231. http://dx.doi.org/10.1002/asi.23032

Storch, N. (2002). Patterns of interaction in ESL pair work. Language Learning, 52(1), 119-158. http://dx.doi.org/10.1111/1467-9922.00179

Storch, N. (2005). Collaborative writing: Product, process, and students' reflections. Journal of Second Language Writing, 14(3), 153-173. http://dx.doi.org/10.1016/j.jslw.2005.05.002

Storch, N. (2011). Collaborative writing in L2 contexts: Processes, outcomes, and future directions. Annual Review of Applied Linguistics, 31, 275-288. http://dx.doi.org/10.1017/S0267190511000079

Storch, N. (2013). Collaborative writing in L2 classrooms (Vol. 31). Bristol, UK: Multilingual Matters.

Swain, M. (2010). “Talking-it-through”: Languaging as a source of learning. In R. Batstone (Ed.), Sociocognitive perspectives on language use/learning (pp. 112-130). Oxford, UK: Oxford University Press.

Tsui, A. B., \& Ng, M. (2000). Do secondary L2 writers benefit from peer comments? Journal of Second Language Writing, 9(2), 147-170. http://dx.doi.org/10.1016/S1060-3743(00)00022-9

Weissberg, R. (2006). Connecting speaking and writing. Ann Arbor, MI: University of Michigan Press. Wigglesworth, G., \& Storch, N. (2012). What role for collaboration in writing and writing feedback. Journal of Second Language Writing, 21(4), 364-374. http://dx.doi.org/10.1016/j.jslw.2012.09.005

Woo, M., Chu, S. K. W., Ho, A., \& Li, X. (2011). Using a wiki to scaffold primary-school students' collaborative writing. Educational Technology \& Society, 14(1), 43-54.

Corresponding author: Chun Lai, laichun@hku.hk

Australasian Journal of Educational Technology (c) 2016.

Please cite as: Lai, C., Lei, C., \& Liu, Y. (2016). Tablets@university: The nature of collaboration and perceived learning in wiki-based collaborative writing. Australasian Journal of Educational Technology, 32(3), 80-95. 